\title{
Effect of cigarette smoking on liver functions: a comparative study conducted among smokers and non-smokers male in El-beida City, Libya
}

\author{
*Khaled Salem Alsalhen, Rahab Dawood Abdalsalam \\ Department of Chemistry, Sciences College, Omar Al-Mukhtar University, El-beida, Libya
}

\begin{abstract}
Tobacco use is widely spread throughout the world. The effect of smoking on human health are serious and in many cases, deadly. The present study was done to investigate the effect of cigarette smoking on some liver functions in male population in El-beida city, Libya. The study was carried out on thirty Libyan male smokers, who smoked at least 10 cigarettes per day for at least15 years. The group includes smokers with age range between 30-60 years. Non-smokers, (control, $n=30$ ) group were collected with the same range of age for statistical comparison. The whole blood samples were drawn by venipuncture from each member and liver functions test were estimated by a kit method on automatic analyzer (Beckman BUN analyzer, USA). The results of the study revealed a significant increase of malondialdehyde (MDA), which is an indicator of lipid peroxidation and oxidative stress significantly increased in cigarette smokers in groups when compared with control group. While the plasma level of total protein, albumin and total bilirubin decreased during smoking. Cigarette smoking raised alkaline phosphatase (ALP), alanine aminotransferase (ALT), aspartate aminotransferase (AST), plasma total cholesterol and triglycerides in smoker group when compared with non-smoker group. To conclude, cigarette smoking leads to oxidative stress by free radical generation by the mechanism of lipid peroxidation. Smoking exerts negative influence on liver functions test should be carefully interpreted, and further study on the mechanism of the effects is warranted.
\end{abstract}

Key Words: Malondialdehyde, alkaline phosphatase (ALP), alanine aminotransferase (ALT), aspartate aminotransferase (AST), total cholesterol, triglycerides.

\section{INTRODUCTION}

Although tobacco has dangerous effect on human health, it still highly consumed throughout the word (Benowitz et al., 1988). Smoking is one of the most common addictions of modern times. It has been implicated as an etiological agent for various chronic diseases, including a variety of infection, cancers, heart diseases and respiratory illnesses (Mehta et al., 2008; Zhong et al., 2008). Cigarette smoke (CS) contains over 4000 compounds, including at least 200 toxicant, 80 known or suspected carcinogens, large quantities of oxidants and free radicals that induce oxidative stress (de Heens et al., 2008; Abel et al., 2005; Carel and Eviatar, 1985). Moreover, cigarette smoking generates many toxic and carcinogenic compounds harmful to the health, such as nicotine, nitrogen oxides, carbon monoxide, hydrogen cyanide and free radicals (Hoffmann et al., 2001).

Liver functions test are useful tools in clinical practice to assess potential liver diseases, to monitor treatment responses and to predict prognosis of the patients with liver diseases. Liver functions test consists most commonly of serum total protein, albumin, alkaline phosphatase (ALP), total bilirubin (TB), aspartate aminotransferase (AST) and alanine aminotransferase (ALT). Albumin is a well-known negative acute phase protein that acts as a marker of inflammation and has antioxidant properties (Pongpaew et al., 2001), but the underlying biochemical mechanisms in many pathological conditions associated with smoking are not fully understood. Therefore, this study was conducted to investigate the effect of smoking

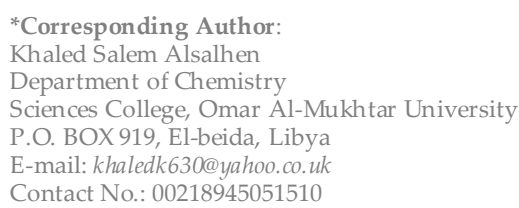

on the inflammatory markers and other biochemical parameters, specifically total protein. However, the interpretation of liver functions test should be comprehensive and careful because these parameters can be influenced by many personal and environmental factors including cigarette smoking (Nathwani et al., 2005). Although in some earlier studies found relationship between smoking and decreased serum protein, albumin and bilirubin concentrations (Dass et al., 2013; Jang et al., 2012; Van Hoydonck et al., 2001). Recently, it has been suggested that smoking does not damage hepatocytes directly, because it does not effect on ALT and AST activities (Dass et al., 2013; Jang et al., 2012). On other hand, Gordon, 1993 found the smoking increased serum ALP levels produced by the bone and the kidney as well as by the liver (Gordon, 1993). However, it still not clear whether smoking is related to each component of liver functions test. Therefore, liver functions test changes in real clinical situations need to be interpreted carefully in the context of the interaction between various life style factors. Moreover, those studies have been reported primarily from Western and Asian countries, while the study of the effects of the cigarette smoking on liver functions test for persons living in Africana countries have had limited study. Thus, this study was conducted in a Libyan population to evaluate the effects of smoking habits on the most commonly used sets of liver functions test on order to consider the interactive association with major demographic factors.

\section{MATERIALS AND METHODS}

Design of the study

This study was conducted among thirteen Libyan male voluntary cigarette smokers (test) and thirteen male nonsmokers (control) aging between 30-60 years. The research project was approved by ethics review committee at Omar Al-Mukhtar University (ref. no. - HE26May2014-DO3343). 


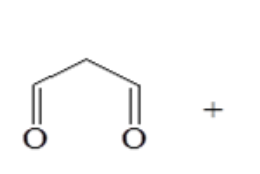

Malondialdehyde (MDA)<smiles>CC1CC(=O)NC(=S)N1</smiles>

Thiobarbituric acid (TBA)<smiles>O=C1NC(=S)NC(=O)C1=CC=Cc1c(O)nc(S)[nH]c1=O</smiles>

TBA-MDA Complex

Figure 1: Thiobarbituric acid reaction (Gerard-Monnier et al., 1997).

Two groups (smokers and non-smokers) were collected with the same range of age for statistical comparison. The smokers were regularly consuming minimum of 10 cigarettes per day for at least 15 years. The smokers were collected in El-beida city during the period (November 2013- February 2014). The enrolled subjects did not have any serious health problem; no history of drug usage and none had donated or received blood in last 6 months. The clinical data, medical history and other relevant information were collected from subjects by personal interview.

\section{Evolution of Liver Function Tests}

$5 \mathrm{ml}$ of whole blood samples were drawn by venipuncture from each member and placed in a heparinized tube and centrifuged at $3000 \mathrm{rpm}$ for 15 minute. Plasma levels of total bilirubin, alkaline phosphatase (ALP), alanine aminotransferase (ALT), aspartate aminotransferase (AST), plasma total cholesterol, triglycerides, total protein and albumin were estimated in all subjects by a kit method on automatic analyzer (Beckman BUN analyzer, USA). Commercially available test kits, products of Analyticon Biotechnologies, Germany were used and with the manufacturer's instruction s strictly adhered to. Plasma globulin was determined as the difference between plasma total protein and albumin.

\section{Determination of Plasma Malon dialdehyde (MDA)}

The assessment of the lipid peroxidation process is achieved via determining the end product MDA. The level of serum MDA was determined spectrophotometrically with a thiobarbituric acid (TBA) solution. In brief, to $150 \mu \mathrm{l}$ serum sample the following were added: $1 \mathrm{ml}$ $(17.5 \%)$ trichloroacetic acid (TCA) and $1 \mathrm{ml}$ of $0.66 \% \mathrm{TBA}$, mixed well by vortex, incubated in boiling water for 15 minutes, and then allowed to cool. One $\mathrm{ml}$ of $70 \%$ TCA was added and the mixture allowed to stand at room temperature for 20 minutes, centrifuged at 2000rpm for 15 minutes, the supernatant was taken out for spectrophotometer assay at 532nm (figure 1) (Muslih et al., 2002).

The concentration of MDA calculated as follow:

$\operatorname{MDA}(\mu \mathrm{mol} / \mathrm{l})=\frac{\text { Absorbance at } 532 \mathrm{~nm}}{\mathrm{~L} \times \mathrm{Eo}} \times \mathrm{D} \times 10^{6}$

L: light path $(1 \mathrm{~cm})$.

E0: Extinction coefficient $1.56 \times 10^{5} \mathrm{M}^{-1} \cdot \mathrm{cm}^{-1}$

D: Dilution factor.

\section{Statistical analysis}

All data are expressed as mean \pm standard division $(\mathrm{M} \pm \mathrm{SD})$, and statistical analysis was carried out using statistically available software (SPSS) version 22.0. Unpaired t-test were applied to test the significance of variance $(p<0.05)$ of the parameters under study between control and smokers groups.

\section{RESULTS AND DISCUSSION}

Table 1 demonstrates general characteristics of Libyan male smokers and non-smokers group. The mean age of male smokers and non-smokers were $49.11 \pm 10.53$ and $47.97 \pm 9.83$ years, respectively. The non-smokers subjects were having weight of $73.13 \pm 13.16$ and smokers were having $71.82 \pm 11.20 \mathrm{~kg}$.

The level of MDA in smokers group significantly increased with mean value $(3.856 \mu \mathrm{mol} / 1 \pm 0.213)$ when compared with its control group $(2.637 \mu \mathrm{mol} / 1 \pm 0.253)$. This result is similar to Aula and Qadir, 2013 and Durak et al., 2002 and Schmid et al., 1996 published reports. CS is known to contain a large number of oxidants; it has been hypothesized that many of the adverse effects of smoking may result from oxidative damage to critical biologic substances (Skurnik and Shoenfeld, 1998). Two major phases were identified in CS: a tar phase and a gas phase: both phases are rich in oxygen-centered, carbon-centered and nitrogen-centered free radicals as well as non-radical oxidants. From the analysis of each phase, it was estimated that a single cigarette puff contains approximately 1014 free radicals in the tar phase and 1015 radicals in the gas phase. These include various compounds, which are capable of causing an increase in the generation of various ROS like superoxide $\left(\mathrm{O}_{2}{ }^{\bullet-}\right)$ hydrogen peroxide $\left(\mathrm{H}_{2} \mathrm{O}_{2}\right)$, hydroxyl $\left(\mathrm{OH}^{*}\right)$ and peroxyl $\left(\mathrm{ROO}^{\circ}\right)$ radicals. These ROS, in turn, are capable of initiating and promoting oxidative damage in the form of lipid peroxidation (Pasupathi et al., 2009). (Durak et al., 2002) suggested that smoking creates a significant oxidant load in the erythrocytes. As a result, toxic free radicals and other oxidant substances in CS damages unsaturated fatty acids and some other oxidation- sensitive structures in the erythrocytes leading to MDA level increase.

In a recent study, increased MDA levels have been reported in blood samples from chronic smokers compared to non- smokers (Aula and Qadir, 2013). In some other studies it has been established that smokers need more antioxidant vitamins, suggesting that antioxidant supplementation is vital for smokers and scavenging potentially harmful free radicals produced by CS (Brown et al., 1987).

Compared to never-smokers and current-smokers had higher levels of plasma total cholesterol, triglycerides, ALT, AST and ALP. However, plasma total protein, albumin and plasma bilirubin levels were lower in smokers than never-smokers (Table 2). All of these differences were statistically significant $(\mathrm{P}<0.05)$.

Cigarette smoke contains high concentration of the gaseous compounds, like carbon monoxide (CO) Nitric oxide (NO) and Nitrogen dioxide $\left(\mathrm{NO}_{2}\right)$ and other substances in cigarettes such as aldehydes, hydrogen cyanide, lead, cadmium etc., In addition, it contains considerable number of free radicals that can be detected (Bridges, 1979). Free radicals are highly reactive atom, which damage the biological membrane through lipid 
Table 1: General characteristic of smokers and non-smokers groups.

\begin{tabular}{ccc}
\hline Characteristics & $\begin{array}{c}\text { Control } \\
\text { (Non-smoker; } \mathbf{n = 3 0 )}\end{array}$ & Smokers (n=30) \\
\hline Age (years) & $47.97 \pm 9.83$ & $49.11 \pm 10.53$ \\
Weight $(\mathrm{kg})$ & $73.13 \pm 13.16$ & $71.82 \pm 11.20$ \\
\hline
\end{tabular}

Data are expressed as mean $\pm \mathrm{SD}$; (n) the number of subjects.

peroxidation. The heavy metal ions lead and cadmium present in smoke is also capable of inducing lipid peroxidation and hence provokes damage of organs propagating lipid peroxidation (Fraga, 1992). In the present study enhanced lipid peroxidation observed in smokers when compared with non-smokers.

Cigarette smoke propagates the lipid peroxidation, which damage the biological cell membrane of the liver and serum aminotransferases are enzymes that act as sensitive indicators of hepatocellular damage (Rochling, 2001). The enzymes are leaked out into blood and increased the level of AST and ALT in smokers when compared non-smokers (Table 2). In our study, we have observed the AST and ALT activities were significantly increased $(\mathrm{P}<0.05)$ in smoker's plasma. The present study is the first to describe a detailed effect of smoking on the individual test of liver functions test. Previous studies showed controversial whether smoking could affect aminotransferase activities (AST and ALT). Some investigators claimed AST increased by cigarette smoking (Chan-Yeung et al., 1981) as our results support, while other studies argued that smoking did not influence AST or ALT (Suriyaprom et al., 2007; Whitehead et al., 1996; Tajima et al., 1988).

Although our results showed elevated ALP levels in the current smoker compared to never having smoked (Table 2). ALP was strongly influenced by smoking, consistent with other studies (Cheung et al., 2009; Wannamethee et al., 2005) concerning osteoporosis have documented increased serum ALP levels in current smokers, as a mainly marker of the liver and bones turnover, but is also present in the kidneys and leukocytes count (Friedman et al., 1995).

The effect of cigarette smoking on biochemical parameters studied is shown in Table 2 . The higher level of serum cholesterol, triglycerides, low plasma protein, albumin levels in smokers group. Various mechanism leading to lipid alteration by smoking are (a) Nicotine increased sympathetic adrenal system leading to increased secretion of catecholamines resulting in increased lipolysis and increased concentration of plasma free fatty acid which further result in increased secretion of hepatic free fatty acids and hepatic triglycerides along with VLDL-cholesterol in the blood stream (b) Presence of hyperinsulinaemia in smokers leads to increased activity of lipoprotein which leads to increased levels of lipid in smokers (Austin, 1991; Rustogi and Shrivastva, 1989). Frohlicha et al., 2003 and Effraim et al., 2000 reported that usage of nicotine like products caused adverse effects like hypercholesterolemia in blood system. Plasma triglycerides determination was also one of the sensitive and detectable biomarkers to cigarette smoking (Kume et al., 2009). Kume et al., 2009 showed the triglyceride levels by cigarette smoking were increased for male smokers. On other hand, acute smoking was negatively associated with total cholesterol and triglycerides concentration (Suriyaprom et al., 2007).

Our study demonstrated that cigarette smoking is associated with significantly lower $(\mathrm{P}<0.05)$ concentrations
Table 2: Effects of cigarette smoking on liver functions of smokers and non-smokers group.

\begin{tabular}{|c|c|c|c|}
\hline Parameters & $\begin{array}{c}\text { Reference } \\
\text { range }\end{array}$ & $\begin{array}{c}\text { Control } \\
(\mathrm{n}=30)\end{array}$ & $\begin{array}{c}\text { Smokers } \\
(n=30)\end{array}$ \\
\hline $\operatorname{ALP}(\mathrm{U} / \mathrm{l})$ & $80-306$ & $139.0 \pm 10.90$ & $240.51^{*} \pm 63.84$ \\
\hline $\operatorname{ALT}(\mathrm{U} / \mathrm{l})$ & $0-40$ & $20.37 \pm 4.33$ & $36.24^{*} \pm 8.79$ \\
\hline AST (U/l) & $0-38$ & $22.72 \pm 3.26$ & $38.06^{*} \pm 9.79$ \\
\hline $\begin{array}{l}\text { Total Bilirubin } \\
\text { (mg/dl) }\end{array}$ & $0.3-1.0$ & $0.88 \pm 0.10$ & $0.30^{*} \pm 0.09$ \\
\hline Total Protein (g/l) & $4.6-8.0$ & $6.91 \pm 0.49$ & $4.03^{*} \pm 1.10$ \\
\hline Albumin (g/l) & $3.8-4.7$ & $4.29 \pm 0.51$ & $2.78^{*} \pm 0.97$ \\
\hline Globulin (g/l) & $2.3-3.5$ & $2.51 \pm 0.81$ & $1.24^{*} \pm 0.71$ \\
\hline $\begin{array}{l}\text { Triglycerides } \\
\text { (mg/dl) }\end{array}$ & $40-160$ & $97 \pm 4.51$ & $203^{*} \pm 12.65$ \\
\hline Cholesterol (mg/dl) & $0-240$ & $218 \pm 20.54$ & $356^{*} \pm 58.12$ \\
\hline
\end{tabular}

Data are expressed as mean $\pm \mathrm{SD}$; (n) the number of subjects.

*Represents significant at $P<0.05$. ALP: Alkaline phosphatise; AST:

Aspartate transaminase; ALT: Alanin transaminase.

of plasma total protein, albumin and bilirubin levels among healthy Libyan men (Table 2). The observation that the smokers in present study had lower plasma albumin concentrations in smokers than non-smokers also suggests the induction of an acute-phase response to smoking, since albumin is a negative acute-phase protein. The lower plasma albumin concentration in smokers agrees with certain (Dales et al., 1974) but not all (Chao et al., 1982). Moreover, there may be dietary effects on albumin synthesis, since smokers have been shown to consume less protein than non-smokers (Thompson et al., 1992). The results of the present study in smoker's subjects confirm these finding and indicate that albumin concentrations were decreased. In addition, cigarette smoking is associated with increased oxidative stress. Albumin also has antioxidant properties by binding copper ions and scavenging hypochlorous acid $(\mathrm{HOCl})$. The scavenging of $\mathrm{HOCl}$ by albumin may be due to the rapid reaction with $\mathrm{SH}$-group rapidly from the circulation and degraded $(\mathrm{Hu}$ et al., 1993; Halliwell, 1988). Cigarette smoking has a powerful influence on WBC count (Frohlicha et al., 2003; Hansen et al., 1990), which may be a marker of exposure to oxidants, the inflammatory response to oxidants (Crowell and Sarnet, 1995). This study confirms higher WBC counts in smokers than never smokers.

Smokers groups resulted in a significant $(\mathrm{P}>0.05)$ decrease in plasma total protein and globulin concentrations. We suggested that the decline in plasma protein and globulin was mainly due to the decrease in albumin level. Additionally, the protein depression in the blood may be due to loss of protein by reduce protein synthesis or increased proteolytic activity due to cigarette smoke exposure or via release of high levels of cellular oxidative free radicals could result increased proteolytic activity (Tetley, 2006). Also, the observed decrease in plasma protein of smokers could be attributed in part to the damaging effect of harmful compounds from cigarette smoking on liver cells as confirmed by the increase in the activities of plasma ALT, AST and ALP in this present study (Table 2).

Our results demonstrated that cigarette smoking is associated with lower concentrations of plasma bilirubin among healthy Libyan men (Table 2). In this study, these significant associations were independent of hemoglobin levels. The association between cigarette smoking and serum bilirubin concentration has been described previously (Schwertner, 1998; Hopkins et al., 1996; ChanYeung et al., 1981). However, cigarette smoking is also found to be positively associated with hemoglobin, which 
regulates bilirubin concentrations (Milman et al., 2001; Micozzi et al., 1989). Therefore, differences in bilirubin levels may be due to hemoglobin concentrations. Still, this study showing the significant associations between total serum bilirubin and smoking were independent of hemoglobin. Regarding the relationship between smoking and bilirubin level have been consistently shown to be lower in current- smokers than never-smokers. Plasma bilirubin was significantly associated with initial stroke severity. It is still unclear why plasma bilirubin, especially direct bilirubin, was significantly associated with initial stroke (Pineda et al., 2008). From a recent study, they found to be a more important determinant of serum bilirubin concentration which that was decline in smokers than never smokers groups (Jaeseong et al., 2012). Bilirubin, which is a bile pigment, is generally regarded as a waste product of heme catabolism. However, it has been suggested that bilirubin might play an important role as an antioxidant, and its role as an antioxidant in vitro has been identified (Minetti et al., 1998; Yamaguchi et al., 1995; Hidalgo et al., 1988). A number of recent in vitro studies have shown that bilirubin is more efficient than $\alpha$ tocopherol at inhibiting low-density lipoprotein (LDL) oxidation and is a more efficient protector of human ventricular myocytes than either vitamin $C$ or vitamin $E$ (Wu et al., 1996; Neuzil and Stocker, 1994; Wu et al., 1994). In this study, low serum bilirubin levels could have been caused by increased level of free radicals produced mostly by cigarette smoking.

\section{CONCLUSION}

In conclusion, we show in the present study that smokers have higher plasma concentrations of MDA compared with non-smokers. Heavy smoking was associated with low total protein, globulin and albumin levels and raised AST, ALT and ALP levels. The levels of cholesterol and triglycerides were significantly increased in all smokers as compared to non- smokers. The association of smoking habits and liver functions test should be carefully analyzed and interpreted. Further studies on the mechanisms of these associations are warranted. Cigarette smoking decreases serum bilirubin in apparently smoking Libyan men. Bilirubin is inexpensive and easily measured in most clinical laboratories. Further studies are needed to determine if measuring bilirubin is effective in detecting free radicals produced by smoking, which contribute to serious diseases. Thus our study concludes that smokers have higher risk than that of non-smokers. Hence our primary aim is aware the smokers not to habitat or addict to smoking by explaining the harmful effects of smoking and thus protect them from various pathological disease.

\section{ACKNOWLEDGEMENT}

We would like to thank all the volunteers who participated in this study.

\section{REFERENCES}

Abel, G. A., Hays, J. T., Decker, P. A., Croghan, G. A., Kuter, D. J., Rigotti, N. A. (2005). Effects of biodhemically confirmed smoking cessation on white blood cell count. Mayo. Clin. Proc. 80(8): 1022-1028. [DOI]

Aula, F. A., Qadir, F. A. (2013). Effects cigarette smoking on some immunological and hematological parameters in male smoker in Erbil city. Jordan journal of biological sciences (JJBS). 6(2): 159-166.

Austin, M. A. (1991). Plasma triglycerides and coronary heart disease. Arterio. Throm. 11: 2-14. [DOI]

Benowitz, N. L. , Porchet, H., Sheiner, L., Jacob, P. (1988). Nicotine absorption and cardiovascular effects with smokeless tobacco use: comparison with cigarettes and nicotine gum. Clinical pharmacology and therapeutics 44(1): 23-28. [DOI]
Bridges, B. A., Clemmension, J., Suginura, T. (1979). Cigarette smoking does it carry a genetic risk. Mutation research/reviews in genetic toxicology 65(1): 71-81. [DOI]

Brown, K. M., Morrice, P. C., Duthie, G. G. (1994). Vitamin E supplementation suppresses indexes of lipid perox-idation and platelet counts in blood of smokers and non-smokers but plasma lipoprotein concentrations remain unchanged. Am. J. Clin. Nutr. 60(3): 383-387.

Carel, R. S., Eviatar, J. (1985). Factors affecting leukocyte count in healthy adults. Prev. Med. 14(5): 607-619. [DOI]

Chan-Yeung, M., Ferreira, P., Frohlich, J., Schulzer, M., Tan, F. (1981). The effects of age, smoking, and alcohol on routine laboratory tests. Am. J. Clin. Pathol. 75(3): 320-326.

Chao, F. C., Tullis, J. L., Alper, C. A., Glynn, R. J., Silbert, J. E. . (1982). Alteration in plasma proteins and platelet functions with aging and cigarette smoking in healthy men. Thromb. Haemost. 47(3): 259-264.

Cheung, B. M., Ong, K. L.,Wong, L. Y. (2009). Elevated serum alkaline phosphatase and peripheral arterial disease in the United States National Health and Nutrition Examination Survey 1999-2004. Int. J. Cardiol. 135(2): 156-161. [DOI]

Crowell, R.J., Sarnet, J. M. (1995). Invited commentary: why does the white blood cell count predict mortality?. Am. J. Epidemiol.142(5): 499-501.

Dales, L. G., Friedman, G. D., Siegelaub, A. B., Seltzer, C. C. (1974). Cigarette smoking and serum chemistry tests. J. Chronic. Dis. 27(6): 293-307. [DOI]

Dass, B. P., Jaganmohan, P., Sravanakumar, P. (2013). Changes in hematological and biochemical parameters in smokeless tobacco (ST) Chewers in Costal Belt of Andhra Pradesh, India. European Journal of biological sciences 5(1): 29-33. [DOI]

de Heens, G. L., Kikkert, R., Aarden, L. A., Van der Velden, U., Loos, B. G. (2009). Effects of smoking on the ex vivo cytokine production in periodontitis. J. Periodontal. Res. 44(1): 28-34. [DOI]

Diplock, A. T. (1987). Dietary supplementation with antioxidants. Is there a case for exceeding the recommended dietary allowance? . Free Radic. Biol. Med. 3(3): 199-201. [DOI]

Durak, I., Elgün, S., Kemal Bingöl, N., Burak Cimen, M. Y., Kaçmaz, M., Büyükkoçak, S., Serdar Oztürk, H. (2002). Effects of cigarette smoking with different tar content on eryth rocyte oxidant/antioxidant status. Addict. Biol. 7(2): 255-288. [DOI]

Effraim, K. D., Modu, S., Hamzah, H. G. (2000). Effect of crude garlic extract on nicotine induced hyperglycemia and hyperlipidemia in rats. Afr. J. Biomd. Res. 3: 125-127.

Farley, J., Baylink, D. J. (1995). Skeletal alkaline phosphate in serum. Clin. Chem. 41(11): 1551-1553.

Fraga, R. (1992). Lipid peroxidation and free radical damage in cell. Free radical Biol. Med. 3: 329-339.

Frei, B., Stocker, R., Ames, B. N. (1988). Antioxidant defenses and lipid peroxidation in human blood plasma. Proceedings of the national academy of sciences 85(24): 9748-9752. [DOI]

Friedman, L. S., Martin, P., Munoz, S. J. (1996). Liver function tests and the objective evaluation of the patient with liver disease, In: Zakin D, boyer TD, eds. Hepatology: A text book of liver disease (Vol. 41). Philadelphia: PA: WB saunders.

Frohlicha, M., Sundc, S., Loweld, H., Hoffmeistera, A. I., Koeniga, W. (2003). Independent association of various smoking dharacteristics with markers of systemic inflammation in men. European heartjournal 24(14): 1365-1372. [DOI]

Gerard-Monnier, D., Erdelmeier, I., Regnard, K., Moze-Henry, N., Yadan, J. C., Chaudiere, J. G. (1998). Reactions of N-methyl-2-phenlindole with malondialdehyde and 4-hydroxyalkenals. Analytical applications to a colorimetric assay of lipid peroxidation. Chemical research in toxicology 11(10): 1176-1183. [DOI]

Gordon, T. (1993). Factors associated with serum alkaline phosphatase level. Arch. Pathol. Lab. Med. 117(2): 187-190.

Halliwell, B. (1988). Albumin an important extracellular antioxidant? Biochem. Pharmacol. 37(4): 569-571. [DOI]

Hansen, L. K., Grimm, R. H. Neaton, J. D. (1990). The relationship of white blood cell count to other cardiovascular risk factors. Int. J. Epidemiol. 19(4): 881-888. [DOI]

Hidalgo, F. J., Zamora, R., Dillard, C. J., Tappel, A. L. (1990). Can serum bilirubin be an index of in vivo oxidative stress? Med. Hypotheses. 33(3): 207-211. [DOI]

Hoffmann, D., Hoffmann, I., El-Bayoumy, K. (2001). The less harmful cigarette: a controversial issue. a tribute to Ernst L. Wynder. Chem. Res. Toxicol. 14(7): 767-790. [DOI]

Hopkins, P. N., Wu, L. L. , Hunt, S. C., James, B. C., Vincent, G. M., Williams, R. R. (1996). Higher serum bilirubin is associated with 
decreased risk for early familial coronary artery disease. Arterioscler. Thromb. Vasc. Biol. 16(2): 250-255. [DOI]

Hu, M. L., Louie, S., Cross, C. E., Motchnik, P., Halliwell, B. (1993). Antioxidant protection against hypochlorous acid in human plasma. J. Lab. Clin. Med. 121(2): 257-262.

Jang, E. S., Heong, S., Hwang, S., Kim, H., Ahn, S., Lee, J., Lee, D. (2012). Effects of coffee, smoking and alcohol on liver function tests: a comprehensive cross-sectional study. BMC. gastroenterology 12(1): 145. [DOI]

Jo J., Kimm, H., Yun, J. E., Lee, K. J., Jee, S. H. (2012). Cigarette smoking and serum bilirubin subtypes in healthy Korean men: The Korea medical institute study. J. Prev. Med. Public Health 45(2): 105-112. [DOI]

Kume, A., Kume, T., Masuda, K., Shibuya, F., Yamzaki, H. (2009). Dose dependent effect of cigarette smoke on blood biomarkers in healthy volunteers: Observations from smoking and non-smoking. Journal of health sciences 55(2): 259-264. [DOI]

Mehta, H., Nazzal, K., Sadikot, R. T. (2008). Cigarette smoking and innate immunity. Inflamm. Res. 57(11): 497-503. [DOI]

Micozzi, M. S., Albanes, D., Stevens, R. G. (1989). Relation of body size and composition to clinical biochemical and hematologic indices in US men and women Am. J. Clin. Nutr. 50(6): 1276-1281.

Milman, N., Byg, K. E., Mulvad, G., Pedersen, H. S., Bjerregaard, P. (2001). Haemoglobin concentrations appear to be lower in indigenous Greenlanders than in Danes: assessment of haemoglobin in 234 Greenlanders and in 2804 Danes. Eur. J. Haematol. 67(1):23-29. [DOI]

Minetti, M., Mallozzi, C., Di Stasi, A. M., Pietraforte, D. (1998). Bilirubin is an effective antioxidant of peroxynitrite- mediated protein oxidation in human blood plasma. Ardh. Biochem. Biophys. 352(2): 165-174. [DOI]

Muslih, R. D., Al-Nimer, M. A., Al-Zamely, O. M. (2002). The level of Malondialdehyde after activation with $\left(\mathrm{H}_{2} \mathrm{O}_{2}\right.$ and $\left.\mathrm{CuSO}_{4}\right)$ and inhibited by Desferoxamine and Molsidomine in the serum of patients with acute myocardial infection. Nat. J. Chem. 5: 148-149.

Nathwani, R. A., Pais, S., Reynolds, T. B., Kaplowitz, N. (2005). Serum alanine aminotransferase in skeletal muscle diseases. Hepatology. 41(2): 380-382. [DOI]

Neuzil, J., Stocker, R. (1994). Free and albumin-bound bilirubin are efficient co-antioxidants for alpha-tocopherol, inhibiting plasma and low density lipoprotein lipid peroxidation. J. Biol. Chem. 269(24): 1671216719.

Pasupathi, P., Bakthavathsalam, G. Y., Rao, Y., Farook, J. (2009). Cigarette smoking-Effect of metabolic health risk: A review. Diabetes and metabolic syndrome: Clinical research and reviews. 3(2): 120-127. [DOI]

Pineda, S., Bang, O. Y., Saver, J. L., Starkman, S., Yun, S. W., Liebeskind, D. S. (2008). Association of serum bilirubin with ischemic stroke outcomes. J. Stroke Cerebrovasc Dis. 17(3): 147-152. [DOI]

Pongpaew, P., Tungtrongchitr, R., Phonrat, B., Vudhivai, N., Viroonudomphol, D., Peter Schelp, F. (2001). Tobacco smoking in relation to the phenotype of alpha-1-antitrypsin and serum vitamin $C$ concentration. Journal of nutritional and environmental medicine 11(3): 167-173. [DOI]

Rochling, F. A. (2001). Evaluation of abnormal liver tests. Clin. Cornerstone. 3(6): 1-12. [DOI]
Schmid, P., Karanikas, G., Kritz, H., Pirich, C., Stamatopoulos, Y., Peskar, B. A., Sinzinger, H. (1996). Passive smoking and platelet thromboxane. Thromb. Res. 81(4): 451-460. [DOI]

Schwertner, H. A. (1998). Association of smoking and low serum bilirubin antioxidant concentrations. Atherosclerosis 136(2): 383-387. [DOI]

Skurnik, Y., Shoenfeld, Y. (1998). Health effects of cigarette smoking. Clin. Dermatol. 16(5): 545-556. [DOI]

Suriyaprom, K., Harn roongroj, T., Namjuntra, P. Chantaranipapong, Y. Tungtrongchitr, R. (2007). Effects of tobacco smoking on alpha-2 macroglobulin and some biochemical parameters in Thai males. Southeast Asian J. Trop. Med. Public Health 38(5): 918-926.

Tajima, K., Takeuchi, K., Suzuki, S. (1988). Risk factors for liver dysfunction in middle aged men based on four year health examination data. Journal of occupational health 40(4): 339-344. [DOI]

Tetley, T. D. (2006). Proteinase inhibitors/secretory leukoprotease inhibitor and elafin. In: Laurent GJ, Shapiro SD, editors. Encyclopedia of respiratory medicine. London: Academic Press.

Thompson, R. L, Margetts, B. M., Wood, D. A. (1992). Cigarette smoking and food and nutrient intakes in relation to coronary heart disease. Nutr. Res. Rev. 5(1): 131-152. [DOI]

Van Hoydonck, P. G. A., Temme, E. H. M., Schouten, E. G. (2001). Serum bilirubin concentration in a Belgian population: the association with smoking status and type of cigarettes. International journal epidemiological 30(6): 1465-1472. [DOI]

Wannamethee, S. G., Lowe, G. D., Shaper, A. G., Rumley, A., Lennon, L., Whincup, P. H. (2005). Associations between cigarette smoking, pipe/cigar smoking, and smoking cessation, and haemostatic and inflammatory markers for cardiovascular disease. Eur. Heart J. 26(17):1765-1773. [DOI]

Whitehead, T. P., Robinson, D., Allaway, S. L. (1996). The effects of cigarette smoking and alcohol consumption on serum liver enzyme activities: a dose-related study in men. Annals of clinical biochemistry: An international journal of biochemistry and laboratory medicine 33(6): 530-535. [DOI]

Wu, T. W., Fung, K. P., Wu, J., Yang, C. C., Weisel, R. D. (1996). Antioxidation of human low density lipoprotein by unconjugated and conjugated bilirubins. Biochem. Pharmacol. 51(6) 859-862. [DOD]

Wu, T. W., Fung, K. P., Yang, C. C. (1994). Unconjugated bilirubin inhibits the oxidation of human low density lipoprotein better than Trolox. Life Sci. 54(25): PL477-481. [DOI]

Yamaguchi, T., Horio, F. , Hashizume, T., Tanaka, M., Ikeda, S., Kakinuma, A. (1995). Bilirubin is oxidized in rats treated with endotoxin and acts as a physiological antioxidant synergistically with ascorbic acid in vivo. Biochem. Biophys. Res. Commun. 214(1): 11-19. [DOI]

Zhong, C. Y., Zhou, Y. M., Pinkerton, K. E. (2008). NF-kappaB inhibition is involved in tobacco smoke-induced apoptosis in the lungs of rats. Toxicol. Appl. Pharmacol. 230(2): 150-158. [DOI] 